\title{
A Few Points about the Teaching of Numerical Analysis Lian Xue $\mathrm{e}^{1, \mathrm{a}^{*}}$ \\ ${ }^{1}$ School of Computer and Computing Science, Zhejiang University City College \\ Hangzhou, 310015, P.R. China \\ $\mathrm{a}^{*}$ xuel@zucc.edu.cn \\ * please mark the corresponding author with an asterisk
}

Keywords: Education in University; Numerical Analysis; Special Course

\begin{abstract}
Numerical analysis is one of the major subjects for the students in the department of mathematics. The present paper studies the three teaching methods in numercial analysis-the instruction on the class, the experiment on the computer, the methods of examination. Then, it concludes that the numerical analysis can be easily learnt by teacher's instruction and the numerical method be clearly shown by electrical courseware. Furthermore, it discusses that the students' mathematical thinking and research ability can be improved by reforming the methods of the experiments and the examination. At last, it gives some practical methods to arouse the students' learning enthusiasm.
\end{abstract}

\section{Introduction}

Numerical analysis is the major course of computational mathematics in the university mathematics department, it focuses on how to deal with practical engineering problems by using the numerical method. Today, with the rapid development of information science and computer technology, the numerical methods studied in this course are even more important [1,2]. The most obvious difference between the course of numerical analysis and other mathematics courses is the perfect combination of theory and practice, it contains both rigorous mathematical theory, but also has a strong practical value.

When the course of numerical analysis was used as a common course in university engineering, we emphasized its unique application [3,4]. And when it comes to a professional course of college mathematics, we need to emphasize both its theoretical structure and practical value. Therefore, the numerical analysis course of mathematics department is generally divided into three major aspects to explain: numerical algebra, digital approximation, numerical solutions of differential equations $[5,6]$. Now, with the compression of university teaching time, these three courses have been combined into a professional required course_ _ numerical analysis, which also increases the difficulty of teaching this course. At present, the numerical analysis course is generally composed of the following three parts: office coaching, the experiment on the computer, and final assessments [7,8]. In order to cultivate the overall quality of the students, these three parts should have a clear division of labor.

\section{Office Coaching}

Office coaching is the most important part of numerical analysis teaching, we should use this part to highlight the characteristics of the numerical analysis course as much as possible. Due to the problems in numerical analysis are refined from the actual situation, then using mathematical theory to deduce, and finally put forward specific solutions. Therefore, each kind of numerical methods of teaching are supposed to put forward from the instances, to guide the students to think how to use mathematical knowledge to solve the mathematical structure, and then give the corresponding theory. In fact, the teaching process of numerical analysis is just a simple process of scientific research. This kind of 
teaching method can stimulate students' interest in learning, make students master knowledge more solidly. However, the content arrangement of most numerical analysis textbooks is to first give theoretical conclusions, and then from top to bottom, to guide the practice by theory, and such deduction is not suitable for most students. The author teaches numerical analysis professional courses for more than ten years and has tried to use deductive method to teach for several times, however, the effect is often unsatisfactory. But, if we start from the actual and present facts, take examples as the pioneer, let the students understand the teaching method of the actual background of the problem first, but often can get twice the result with half the effort. The contemporary physicist Nobel Laureate Yang Zhenning once published a view on mathematics education. He advocated the cultivation of applied mathematicians. Before learning pure mathematics, should let him accept the enthusiasm and training of some physicists, it means so. Through surveys, students reflect this learning method is conducive to them to understand some of the original thinking of mathematicians to solve practical problems.

At the same time, we must pay attention to the structure of the numerical analysis course in teaching. When students are newly exposed to this course, they often find the course difficult, even harder than mathematical analysis, and they find it difficult to keep up with the teacher's thinking. In the course of time, students' interest in learning gradually diminishes. The main reason for this situation is that the knowledge of numerical analysis is composed of many different parts and the structure is relatively loose. If there isn't a good thinking backbone throughout. After the students have finished the whole course, they can only accumulate a mixture of knowledge, but can not understand the relationship between the knowledge structures deeply. Therefore, teachers are required to strive to maintain a close connection between the chapters in the process of teaching, indicating that the general idea of numerical analysis is "approximate solution". The logic of mathematics is very strong, and numerical analysis is certainly not an exception. Teachers in the teaching process should gradually ask questions in depth and guide students to see the connections and differences between various knowledge points. When a new question is asked, students need to be inspired to think about why such questions are raised, and where the flaws of the original method are. In this way, the students' thinking will be clearer. For example, in the teaching of interpolation, first we need to solve the problems of the existence and uniqueness of solutions of polynomial interpolation, and then solve the expression. Thus the Lagrange interpolation method is obtained. By analyzing its properties, it is found that the computational load increases with the addition of nodes, which leads to Newton interpolation that saves computations. Then the Runge phenomenon is introduced into Hermite interpolation and segmentation interpolation, and finally the spline interpolation is given, thus, interpolate this knowledge point will be coherent and easily understood.

In addition, in the teaching process, We can properly use modern teaching methods_electronic teaching. Electronic teaching is one of the various teaching methods at present, but it does not become a major part of mathematics teaching, we should "rational use modern teaching methods and tools, and we must not rely too much on multimedia courseware." Electronic teaching can play an auxiliary role in the teaching of numerical analysis. The main feature of this teaching method is to improve the drawbacks of teachers' blackboard writing, and the content information is large and vivid. In numerical analysis teaching, we can show some examples of numerical analysis, graphics and other content to students in this way. Thus, the student's impression will be deeper and more stimulating, and it will also inspire students' intuitive understanding of the problem. In addition, the electronic teaching plan can help students connect the contents of the course together when reviewing the course, and better help students to recall and review. However, the teaching of ordinary courses is mainly based on the blackboard, because the process of mathematical reasoning on the blackboard is also a process of students' digestion and understanding of knowledge. 


\section{The Experiment on the Computer}

The experimental class on the computer is the most obvious difference between the numerical analysis and other mathematics classes $[9,10]$. The main purpose of this class is to develop students' practice and programming skills, and apply the theory of numerical analysis methods learned in class to specific examples. This is a process of digesting the knowledge points learned in class. Students can try different ways to solve the same problem, and compare these methods to verify the advantages and disadvantages of various methods. Problems in numerical analysis rely on classroom teaching, theoretical derivation is difficult to understand. For example, convergence Problems such as sex, stability, etc. Students can deepen their understanding of the classroom knowledge in the actual calculation process through drawing or list or other comparisons.

The combination of the experiment on the computer and classroom teaching is also a primary scientific research process. This allows students to initially experience the fun, difficulties, and atmosphere of scientific research. However, it should be noted that there are also significant problems in the teaching experiment of the experiment on the computer - the repetition of internship topics and plagiarism among students. The author tried to divide the students into groups for different topics, or for the same subject, using many different methods for solving parameters, then compare the differences between them. The results of this approach are ideal, but there are still a lot of improvements in the teaching of the experimental part of the computer.

\section{The Method of Assessing and Urging Learning}

Assessment is the final part of each course and it is necessary to set it reasonably. According to the characteristics of numerical analysis courses, apart from the usual results, the numerical experiment should be placed within the scope of assessment, and the written report on the machine is the content of the assessment. In addition, we have attempted to combine the oral and written tests for assessment. The students tell the teacher about the method, theory, and numerical analysis of a problem and further analyze the differences between the various methods. This approach has yielded great results. It urges students to scrutinize the textbook knowledge and the results of the test on the computer. This will enable students to deepen their understanding of the content of textbooks.

Homework is one of the contents of the assessment, and numerical analysis is a mathematics course, doing more exercises is one of the most direct means of learning mathematics. The theoretical derivation process in many textbooks can't be simply understood by the mind alone. It is difficult to understand the contents of the book without doing a certain amount of exercises. We know that teaching is twofold and that students' own efforts are of course essential, but only rely on the consciousness of the students for most of the students is not realistic. Especially in modern times where business climate is very strong, studying mathematics is the last resort for most students. Chen Shengshen, the great geologist, once said, "If a person's purpose is fame and fortune, then mathematics is not a shortcut." Therefore, it is necessary to adopt the necessary means, such as the revision of the regular assignment, the proper test and the result of the result. Therefore, it is necessary to use some necessary means, such as periodical corrections, proper tests and record the results into the grades.

At the same time, we also can urge the students to see some reference books. Because of the breadth of knowledge involved in numerical analysis, it also makes its content flexible and changeable. Through the survey, students reflected that reading more reference books is an important part of learning this course. There are many reference books for numerical analysis, each book has its own style. For a certain class of questions, in some books, these questions are written in detail and in some books these questions are just carried over. A formula can often be exported by many methods. It is beneficial for most students to read more reference books. This way can not only broaden students' horizons, but also consolidate the knowledge they already have. 


\section{References}

[1] Z.C.Shi, The Third Scientific Method- Scientific Computation in the Computing time, Tsinghua University Press, Beijing, 2000.

[2] Z.Li, Application of Math Experiment in the University Mathematics Teaching, Neijiang Technology, 28(2007)11-14.

[3] Q.Fu, A Brief Talk on the Students General Ability of Cultivating, Higher Engineering Education Research, 12(2002)86-88.

[4] D.Kincaid, Numerical Analysis :Mathematics of Scientific Computing, Tsinghua University Press, Beijing, 2003.

[5] R.L.Burden, J.D.Faires, Numerical Analysis, Higher Education Press, BeiJing, 2001.

[6] C.N.Yang, On the application of math teaching and research, Yang Zhenning Speech Set, Nankai University Press, TianJin, 1985.

[7] C.N.Yang, On the application of math teaching and research, Yang Zhenning Speech Set, Nankai University Press, TianJin, 1985.

[8] Q.Fu, On the Students General cultivate the ability of students, Higher Engineering Education Research, 12(2002)86-88.

[9] Z.Li, Experimental Math at the University Mathematics Teaching, Neijiang Technology, 28(2007)11-12.

[10]Q.Fu, Brief discussion about cultivating the students' comprehensive ability, Researches in Higher Education of Engineering, 12(2002)86-88. 